\title{
Whole grain food intake elevates serum enterolactone
}

\author{
David R. Jacobs $\mathrm{Jr}^{1,2 *}$, Mark A. Pereira ${ }^{3}$, Katariina Stumpf ${ }^{4}$, Joel J. Pins ${ }^{5}$ and Herman Adlercreutz ${ }^{4}$ \\ ${ }^{1}$ Division of Epidemiology, School of Public Health, University of Minnesota, Minneapolis, MN, USA \\ ${ }^{2}$ Institute for Nutrition Research, University of Oslo, Oslo, Norway \\ ${ }^{3}$ Department of Pediatrics, Harvard Medical School and Children's Hospital, Boston, MA, USA \\ ${ }^{4}$ Institute for Preventive Medicine, Nutrition, and Cancer, Folkhälsan Research Center, and Division of Clinical Chemistry, \\ University of Helsinki, Finland \\ ${ }^{5}$ Department of Family Practice and Community Health, University of Minnesota Medical School, University of Minnesota, \\ Minneapolis, MN, USA
}

(Received 8 June 2001 - Revised 18 February 2002 - Accepted 11 March 2002)

\begin{abstract}
Both intake of whole grain and higher levels of serum enterolactone have been related to reduced risk for CHD and some cancers. Because lignans are prevalent in the outer layers of grains, these findings may be related. We carried out a crossover feeding study in which overweight, hyperinsulinaemic, non-diabetic men ( $n$ 5) and women $(n$ 6) ate, in random order, wholegrain foods or refined-grain foods in a diet with $30 \%$ energy from fat. The dominant whole grain was wheat, followed by oats and rice. All food was supplied by the investigators and each diet lasted for 6 weeks, with an intervening washout period of 6-9 weeks. Serum enterolactone concentrations were higher when eating the wholegrain than the refined-grain diet by 6.2 (within person SE 1.7$) \mathrm{nmol} / \mathrm{l}(P=0.0008)$. Most of the increase in serum enterolactone when eating the wholegrain diet occurred within 2 weeks, though the serum enterolactone difference between wholegrain and refined-grain diets continued to increase through 6 weeks. Serum enterolactone concentrations can be raised by eating a diet rich in whole grains.
\end{abstract}

Phyto-oestrogens: Feeding study: Wholegrain food

There is considerable interest in the possibility that intake of wholegrain foods rich in phytochemicals such as phytooestrogens may play a role in reducing risk of several chronic diseases, including CHD, diabetes and cancer (Jacobs et al. 1999; Wiseman, 1999; Tikkanen \& Adlercreutz, 2000; Wiseman et al. 2000). The phytooestrogens pinoresinol, lariciresinol, syringaresinol, secoisolariciresinol and matairesinol, which are plant lignans, are converted into the mammalian lignans enterolactone and enterodiol by intestinal bacteria (Borriello et al. 1985; Glitsø et al. 2000; Heinonen et al. 2001) and subsequently absorbed. Studies by Adlercreutz et al. (1998) and Stumpf et al. (2000b), using a time-resolved immunofluorometric assay, have demonstrated that the risk of incident heart disease was reduced in Finnish men whose serum enterolactone concentrations were in the upper quartile (Vanharanta et al. 1999). Lignan intake may also be related to cancer risk (Thompson, 1998; Ford et al. 1999). In a case-control study of 194 Finnish women with breast cancer (who entered the study before diagnosis) and 208 controls, the odds ratio in the highest quintile of enterolactone values adjusted for all known risk factors for breast cancer was 0.38 (Pietinen et al. 2001).

In the Finnish population, much of the lignan intake is believed to come from whole rye foods, as well as vegetables and berries (Adlercreutz et al. 1987; Stumpf et al. 2000a; Kilkkinen et al. 2001). Whole rye is rarely available in the USA; however, wholewheat and other wholegrain foods may also be important sources of phyto-oestrogens. If so, those who eat more wholegrain foods generally would be expected to have higher serum enterolactone than those who eat more refined-grain foods.

Based on our observation of reduced CHD (Jacobs et al. 1998) and diabetes (Meyer et al. 2000) in women from IA, USA, who habitually ate wholegrain foods, and of reduced fasting insulin in young adults who habitually ate wholegrain foods (Pereira et al. 1998), we carried out a crossover feeding study to compare metabolic differences in hyperinsulinaemic, overweight men and women when eating a diet high in wholegrain foods compared with one high in refined-grain foods, all other foods being identical between the two diets. In the present paper, we report serum 
enterolactone levels while consuming these two diets, with the prior hypothesis that intake of wholegrain foods, compared with intake of refined-grain foods, increases serum enterolactone.

\section{Subjects and methods}

\section{Study design}

During 1998 and 1999, we conducted a randomized, nonblinded, crossover, controlled feeding trial, fully described elsewhere (Pereira et al. 2002). There were two 6-week feeding periods and a washout period of 6-9 weeks. During feeding periods, the participants were asked to consume all of the food provided to them by the metabolic kitchen of the General Clinical Research Center, University of Minnesota, and no other food, except for energy-free beverages. One day from the $6 \mathrm{~d}$ menu cycle is presented in Table 1. Each participant received the wholegrain or refined-grain diet during the first feeding period and then was fed the other diet during the second period. Energy intake for each person was based on the Harris-Benedict equation (Harris \& Benedict, 1919). It was calibrated to maintain weight after the first $10 \mathrm{~d}$ of feeding during period 1; specifically, energy intake had to be reduced in only one participant eating whole grain and one eating refined grain at that time. There was no statistically significant weight change during the remainder of the study. Each diet contained about twelve $30 \mathrm{~g}$ servings per $\mathrm{d}$ of foods (about eight eating occasions) made with grain flour. Wholegrain foods, including bran and germ as well as endosperm, were substituted isovolumically for refinedgrain foods, which excluded bran and germ. Therefore, the wholegrain foods contributed to a slightly lower energy intake. White bread and refined wheat, rice and corn products were substituted with commercially available wholegrain items, of which about $80 \%$ were wheat and the remainder oats, rice, corn, barley and rye. The refined-grain diet had $54.6 \%$ energy as carbohydrate, $15.7 \%$ as protein and $30.7 \%$ as fat. The corresponding wholegrain diet had $54.2 \%$ energy as carbohydrate, $17.1 \%$ as protein and $31.7 \%$ as fat. The saturated: monounsaturated:polyunsaturated fatty acid goal was 1:1:1. The cholesterol content was controlled at a level of $100 \mathrm{mg} / 4 \cdot 18 \mathrm{MJ}(1000 \mathrm{kcal})$. Dietary fibre intake was 17 and $28 \mathrm{~g} / 8.36 \mathrm{MJ}$ (2000 kcal) energy intake in the refined- and wholegrain diets respectively. Because the substitution of wholegrain for refined grain was isovolumic and the bran and germ contained little energy, the wholegrain diet contained $8.13 \mathrm{MJ}(1943 \mathrm{kcal})$ for every $8 \cdot 36 \mathrm{MJ}(2000 \mathrm{kcal})$ in the refined-grain diet. Nutrient calculations were performed using the Nutrition Data System for Research software, version 4.02 (University of Minnesota, Minneapolis, MN, USA).

\section{Subject recruitment}

Twelve subjects (six women and six men), recruited from the University of Minnesota and surrounding community, were aged between 26-54 years, had BMI between 27 and $36 \mathrm{~kg} / \mathrm{m}^{2}$, and fasting insulin between 96 and $288 \mathrm{pmol} / \mathrm{l}$, were non-diabetic, non-smokers and otherwise

Table 1. Sample menu from the refined and wholegrain diets*

\begin{tabular}{|c|c|c|c|c|c|c|c|}
\hline Breakfast & $\begin{array}{l}\text { Amount } \\
\text { (g) }\end{array}$ & Lunch & $\begin{array}{l}\text { Amount } \\
\text { (g) }\end{array}$ & Dinner & $\begin{array}{l}\text { Amount } \\
\text { (g) }\end{array}$ & $\begin{array}{l}\text { Late night } \\
\text { snack }\end{array}$ & $\begin{array}{l}\text { Amount } \\
\text { (g) }\end{array}$ \\
\hline Orange juice & 140 & Pasta salad: & & $\begin{array}{l}\text { Lemon dill fish } \\
\text { on rice: }\end{array}$ & & $\begin{array}{l}\text { Ritz crackers - } \\
\text { wheat thins } †\end{array}$ & 25 \\
\hline $\begin{array}{l}\text { Rice chex-wheat } \\
\text { chext }\end{array}$ & 30 & $\begin{array}{l}\text { TriColor rotini-wholewheat } \\
\text { TriColor elbow noodle, } \\
\text { cooked } †\end{array}$ & 150 & $\begin{array}{l}\text { Rice-brown rice, } \\
\text { cooked } †\end{array}$ & 170 & String cheese & 30 \\
\hline $\begin{array}{l}\text { Banana muffin- } \\
\text { wholewheat muffin† }\end{array}$ & 75 & $\begin{array}{l}\text { Chicken breast, } \\
\text { cooked }\end{array}$ & 75 & Safflower oil & 6 & Grape juice & 100 \\
\hline Promise margarine & 5 & Black olives & 30 & $\begin{array}{l}\text { Orange roughy } \\
\text { (raw weight) }\end{array}$ & 85 & & \\
\hline $2 \%$ Milk & 180 & Green pepper & 20 & Lemon juice-dill & Dash & & \\
\hline $\begin{array}{l}\text { Coffee-tea-herbal } \\
\text { tea }\end{array}$ & & Carrot, raw & 50 & Broccoli & 80 & & \\
\hline Sugar & 6 & $\begin{array}{l}\text { Wishbone Italian } \\
\text { dressing }\end{array}$ & 6 & $\begin{array}{l}\text { Salad: } \\
\text { Lettuce mix }\end{array}$ & 50 & & \\
\hline \multirow[t]{6}{*}{ Orange juice } & 140 & $\begin{array}{l}\text { Fat-free Italian dressing } \\
\text { Egg yolk }\end{array}$ & $\begin{array}{r}20 \\
5\end{array}$ & $\begin{array}{l}\text { With tomato \& onion } \\
\text { Regular ranch } \\
\text { dressing }\end{array}$ & $\begin{array}{r}30 / 15 \\
10\end{array}$ & & \\
\hline & & $\begin{array}{l}\text { Bread stick-mixed grain } \\
\text { bread } †\end{array}$ & 35 & $\begin{array}{l}\text { French bread-100\% } \\
\text { wholewheat bread } †\end{array}$ & 35 & & \\
\hline & & Promise margarine & 6 & Butter & 4 & & \\
\hline & & $\begin{array}{l}\text { Gingersnap-wholewheat } \\
\text { gingersnap } t\end{array}$ & 25 & Fruit cocktail & 100 & & \\
\hline & & Salt-pepper-herbs & & Salt-pepper-herbs & & & \\
\hline & & Coffee-tea-herbal tea & & $\begin{array}{l}\text { Coffee-tea-herbal } \\
\text { tea }\end{array}$ & & & \\
\hline
\end{tabular}

\footnotetext{
* This menu is one of six menus that were rotated over the two 6-week treatment periods
} † Grain foods (refined-grain - whole grain). 
healthy according to self-report (including specific questions about major chronic diseases). Apart from one participant on hormone-replacement therapy, none was taking any prescription medication at the beginning of the study. Antibiotic use is known to reduce intestinal enterolactone production (Adlercreutz et al. 1986; Kilkkinen et al. 2002). No participant was taking an antibiotic at the beginning of the study; however, we did not inquire about antibiotic use in the months before the study began. The habitual diets of the subjects as reported prior to baseline in a food-frequency questionnaire indicated $40 \%$ energy as carbohydrate, $40 \%$ as fat and $15 \%$ as protein. Dietary fibre was $13.4 \mathrm{~g} / 8.36 \mathrm{MJ}$ (2000 kcal) (lower than in the refined-grain diet because of increased fruits and vegetables in the experimental base diet). Subjects consumed little alcohol and were either sedentary or moderately active in leisure time. Moderately active individuals were encouraged to maintain steady habits throughout the study. One man did not complete the study due to illness during the washout period. His results are entirely omitted from these analyses.

\section{Clinic measurements}

Participants attended the clinic at baseline and after 2, 4 and 6 weeks in each of the two diet periods. Participants were asked to avoid strenuous exercise for $24 \mathrm{~h}$ prior to each clinic visit. On each occasion, the Center's nurses measured height, weight, and blood pressure and drew blood in the morning following a fast of at least $12 \mathrm{~h}$. With the subject seated quietly, blood was then drawn from an antecubital vein into vacutainer tubes. Within $30 \mathrm{~min}$ of phlebotomy, whole blood samples were centrifuged for $10 \mathrm{~min}$ at $2800 \mathrm{~g}$ and 0.5 to $1.0 \mathrm{ml}$ samples of serum were pipetted into polyethylene cryovials. Samples for serum enterolactone were stored at $-70^{\circ} \mathrm{C}$ until shipped in dry ice for analysis in Helsinki, Finland, in 2000. Serum enterolactone was measured by the timeresolved fluoroimmunoassay of Adlercreutz et al. (1998), as slightly modified by Stumpf et al. (2000b).

\section{Statistical analysis}

We present mean values with their standard errors of serum enterolactone at baseline by treatment to establish approximate equality of the starting point under each treatment. However, we did not adjust for the baseline values, because they reflect self-selected and uncontrolled dietary conditions and are assumed to washout during the first 2 weeks of each treatment period. Three of the sixty-six follow-up observations were missing. We analysed the effect of wholegrain $v$. refined-grain diet on serum enterolactone both non-parametrically and parametrically. In the non-parametric analysis, we carried out a sign test, with the null hypothesis that the serum enterolactone difference (wholegrain diet - refined-grain diet) is equally likely to be positive or negative. In the parametric analysis, we used the PROC MIXED ${ }^{\odot}$ program $\left(\mathrm{SAS}^{\odot}\right.$ software, version 6.12; Statistical Analysis Systems Inc., Cary, NC, USA) to perform repeated measures regression of the week 2, 4, and 6 serum enterolactone on treatment

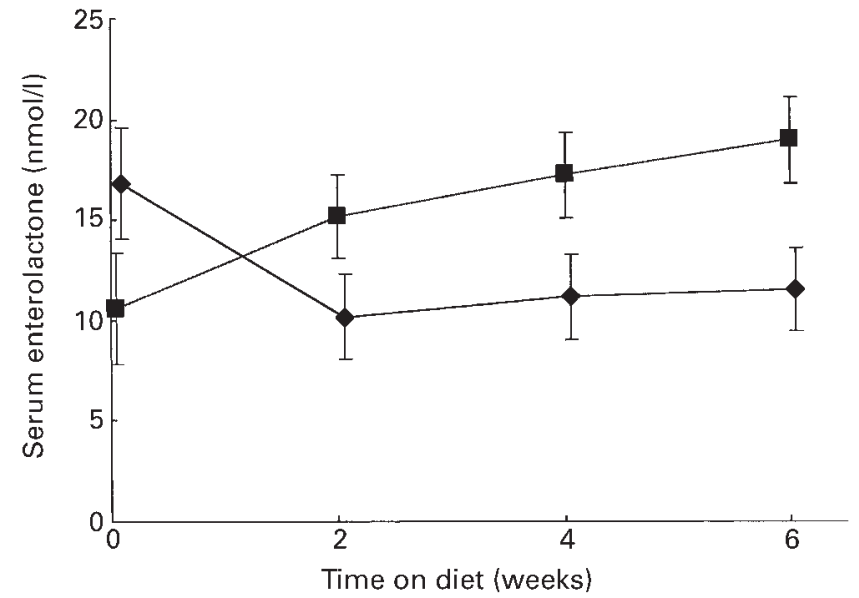

Fig. 1. Serum enterolactone at baseline and during wholegrain and refined-grain feeding. $\bullet$, Refined-grain diet; $\mathbf{\square}$, wholegrain diet. For details of diets, subjects and procedures, see Table 1 and p. 112. Values are means for eleven subjects with standard errors (computed within person) shown by vertical bars. The standard errors are larger at baseline than during follow-up, reflecting the selfselected and uncontrolled diet pre-baseline and during the washout period. The baseline points are not taken into account in the computations.

(whole $v$. refined), time (continuous weeks), feeding period (one v. two) and gender. These findings were presented as the mean treatment differences (with their standard errors, computed from variation within person) observed over the three follow-up time points (weeks 2, 4 and 6). A graphical presentation shows baseline and week-by-week changes by treatment (Fig. 1). This figure was based on the primary model, using discrete time and treatment $\times$ time interaction terms. Standard errors were computed within person, except when between person standard deviations are specified. An additional model included period $\times$ treatment interaction to assess whether the crossover design assumption (no memory in the second diet period of the changes in the first diet period) was violated.

\section{Results}

Compliance to the diets was assessed using reports filled out by each participant every day of the study. The energy level of protocol food not eaten during the two 6week diets did not differ between wholegrain (160 (SD $75) \mathrm{kJ} / \mathrm{d}(38(\mathrm{SD} \mathrm{18}) \mathrm{kcal} / \mathrm{d}))$ and refined grain (222 (SD $125) \mathrm{kJ} / \mathrm{d}(53$ (SD 30) $\mathrm{kcal} / \mathrm{d})$ ); treatments. The same was true of extra (non-protocol) food from sources other than the treatment diets (wholegrain 46 (SD 25) kJ/d (11 (SD 6) $\mathrm{kcal} / \mathrm{d})$ ) refined $63(\mathrm{SD} \mathrm{33)} \mathrm{kJ} / \mathrm{d}(15(\mathrm{SD} \mathrm{8}) \mathrm{kcal} / \mathrm{d})$ ). No side effects were noted. The validity of the crossover design was supported by the observation that period $\times$ time interaction was not significant in any model (results not shown).

Baseline serum enterolactone showed substantial variation between subjects (SD $14.3 \mathrm{nmol} / \mathrm{l}$ ) and within subjects (SD $9.3 \mathrm{nmol} / \mathrm{l}$ ); the intraclass correlation was 0.70 . At baseline, women appeared to have higher serum enterolactone than men by 14.1 (between person SE 9.6) $\mathrm{nmol} / \mathrm{l}$ (baseline mean value $20.1 \mathrm{nmol} / 1$ in women, $6.0 \mathrm{nmol} / 1$ in 
Table 2. Serum enterolactone (nmol/l) for each subject at weeks $0,2,4$ and 6 of each feeding period*

\begin{tabular}{|c|c|c|c|c|c|c|c|c|c|c|c|c|}
\hline \multirow[b]{3}{*}{ Subject† } & \multicolumn{8}{|c|}{ Enterolactone concentration } & \multirow{2}{*}{\multicolumn{4}{|c|}{$\begin{array}{l}\text { Enterolactone concentration difference } \\
\text { (whole-grain diet - refined-grain diet) }\end{array}$}} \\
\hline & \multicolumn{4}{|c|}{ Refined-grain diet } & \multicolumn{4}{|c|}{ Wholegrain diet } & & & & \\
\hline & Week 0 & Week 2 & Week 4 & Week 6 & Week 0 & Week 2 & Week 4 & Week 6 & Week 0 & Week 2 & Week 4 & Week 6 \\
\hline A & $25 \cdot 5$ & $15 \cdot 2$ & $25 \cdot 2$ & $35 \cdot 9$ & $5 \cdot 8$ & $29 \cdot 2$ & $24 \cdot 2$ & $23 \cdot 3$ & $-19 \cdot 7$ & $14 \cdot 0$ & $-1 \cdot 1$ & $-12 \cdot 6$ \\
\hline $\mathrm{B} \ddagger$ & 13.5 & 19.5 & $8 \cdot 1$ & 8.4 & $6 \cdot 8$ & $19 \cdot 8$ & $23 \cdot 0$ & 23.9 & $-6 \cdot 7$ & 0.3 & 14.9 & 15.5 \\
\hline C & $7 \cdot 0$ & 9.9 & $6 \cdot 8$ & $9 \cdot 7$ & $2 \cdot 8$ & $12 \cdot 4$ & $19 \cdot 0$ & $9 \cdot 4$ & $-4 \cdot 2$ & 2.4 & $12 \cdot 2$ & -0.3 \\
\hline D & $80 \cdot 0$ & 28.9 & 28.6 & 31.6 & 41.9 & $56 \cdot 4$ & 39.3 & $30 \cdot 8$ & -38.1 & 27.5 & 10.7 & -0.9 \\
\hline E & 5.4 & 0.2 & 0.0 & 0.0 & 5.8 & 0.1 & $2 \cdot 1$ & 2.9 & 0.4 & 0.0 & $2 \cdot 1$ & 2.9 \\
\hline $\mathrm{F} \S$ & 18.0 & 11.6 & 14.4 & $10 \cdot 7$ & $13 \cdot 1$ & 3.3 & 30.9 & 42.4 & -4.9 & -8.3 & $16 \cdot 5$ & 31.7 \\
\hline $\mathrm{G}$ & $7 \cdot 7$ & $12 \cdot 9$ & $20 \cdot 7$ & $11 \cdot 1$ & $17 \cdot 0$ & $25 \cdot 6$ & - & $46 \cdot 1$ & $9 \cdot 2$ & $12 \cdot 6$ & - & $35 \cdot 1$ \\
\hline $\mathrm{H}$ & $17 \cdot 8$ & 4.7 & 9.9 & 7.2 & 16.9 & - & 9.8 & 17.8 & -0.9 & - & -0.1 & $10 \cdot 6$ \\
\hline I & 1.8 & 0.5 & 1.2 & 1.5 & 0.2 & 0.7 & 1.7 & 0.7 & -1.5 & 0.2 & 0.5 & -0.8 \\
\hline $\mathrm{J}$ & 7.4 & $6 \cdot 8$ & $6 \cdot 8$ & 3.2 & 5.4 & 10.0 & 1.9 & 8.0 & -1.9 & 3.1 & -4.9 & 4.9 \\
\hline $\mathrm{K}$ & $1 \cdot 8$ & 0.6 & - & $2 \cdot 8$ & 0.3 & $2 \cdot 9$ & $11 \cdot 8$ & 5.9 & -1.5 & $2 \cdot 3$ & - & $3 \cdot 1$ \\
\hline
\end{tabular}

-, Not done or non-computable.

* For details of diets, subjects and procedures, see Table 1 and p. 112.

† Subjects B, D, F, G, I, and K ate the refined-grain diet first, while A, C, E, H, and J ate the wholegrain diet first.

$\ddagger$ Subject $B$ took antibiotic for illness after week 2 of the refined-grain diet.

$\S$ Subject $\mathrm{F}$ took antibiotic for illness $2 \mathrm{~d}$ before week 2 of the wholegrain diet.

men, $P=0 \cdot 17$ ). The baseline serum enterolactone did not differ significantly between treatments (mean value $16.8 \mathrm{nmol} / \mathrm{l}$ before the refined-grain diet and $10.6 \mathrm{nmol} / \mathrm{l}$ before the wholegrain diet (within person $\mathrm{SE} 4.0 \mathrm{nmol} / \mathrm{l}$, $P=0 \cdot 15))$.

Table 2 gives the serum enterolactone concentrations for each participant at each measurement point. In non-parametric analysis, serum enterolactone concentration was higher when eating the wholegrain diet than when eating the refined-grain diet in twenty-one of the thirty available post baseline measurement pairs (sign test $\mathrm{z} 2 \cdot 2$, $P=0.028$ ). In parametric analysis, serum enterolactone concentrations were higher when eating the wholegrain than the refined grain diet by 6.2 (within person SE 1.7 ) nmol/l $(P=0 \cdot 0008)$. The week-by-week changes in serum enterolactone are shown in Fig. 1. The difference in serum enterolactone between the wholegrain and refinedgrain diets was evident after 2 weeks. Nevertheless, the serum enterolactone difference between wholegrain and refined-grain diets continued to increase over the 6-week period.

Despite higher serum enterolactone concentrations in women than in men, the wholegrain - refined-grain diet difference was similar in the six women (6.7 (within person SE 2.5) nmol/l, $P=0.009)$ and the five men $(5.6$ (within person SE 2.6) nmol/l, $P=0.04$ ). We note that power to study gender-specific differences is limited in this small study.

Two participants took antibiotics during this feeding study (Table 2). In the first, during the refined-grain diet, serum enterolactone decreased from $19 \mathrm{nmol} / \mathrm{l}$ at study week 2 to $8 \mathrm{nmol} / \mathrm{l}$ at study week 4 shortly after beginning the antibiotic; it remained at $8 \mathrm{nmol} / \mathrm{l}$ at study week 6 . In the second case, during the wholegrain diet, serum enterolactone decreased from $13 \mathrm{nmol} / \mathrm{l}$ at baseline to $3 \mathrm{nmol} / \mathrm{l}$ at study week $2,2 \mathrm{~d}$ after beginning the antibiotic; it increased to $31 \mathrm{nmol} / \mathrm{l}$ at study week 4 and $42 \mathrm{nmol} / \mathrm{l}$ at study week 6 . Omission of these observations from the analysis did not qualitatively alter the findings of this study.

\section{Discussion}

We found that serum enterolactone can be raised by eating a diet containing about twelve $30 \mathrm{~g}$ servings of wholegrain foods/8.36 MJ (2000 kcal) per d, compared with an identical American Heart Association step I diet containing refined instead of wholegrain foods (Krauss et al. 1996). The present controlled feeding study had $85 \%$ statistical power for detecting a wholegrain effect on serum enterolactone as small as $5.1 \mathrm{nmol} / \mathrm{l}$. It demonstrated the possibility of changing serum enterolactone using commercially available wholegrain products (mostly wheat, oats and rice). Lignans may play a causal role in chronic disease risk (Thompson, 1998; Ford et al. 1999; Vanharanta et al. 1999; Pietinen et al. 2001), although it is not known whether the mammalian lignan enterolactone itself is involved in pathogenic processes. Other components of wholegrain and other minimally processed plant foods may also play a role in pathogenesis (Slavin et al. 1999; Pins et al. 2001). At minimum, serum enterolactone may be reflective of whole grain intake, including rye (Juntunen et al. 2000) in the Finnish diet and whole wheat in the US diet (Gerrior \& Bente, 2001).

Many vegetables and berries and some fruits increase the serum enterolactone level. In the present study, the $30 \%$ energy as fat diet included various lignan-containing foods apart from grains, such as oranges, pineapple, blueberry, black olives, carrots, broccoli, onions, green beans, celery, lettuce, peanuts, green pepper, mushrooms and tea (Mazur \& Adlercreutz, 1998). As these foods were present in identical quantities in both wholegrain and refined-grain feeding periods, the observed effect of whole grain intake on serum enterolactone is above and beyond that of other enterolactone-inducing foods. To reach levels of serum enterolactone of more than $30 \mathrm{nmol} / 1$ that were associated with significantly reduced breast cancer risk in women (Pietinen et al. 2001) and acute coronary events in men (Vanharanta et al. 1999), whole grain, vegetable, fruit and berry consumption has to be adequate. In a dietary 
intervention study in a Finnish population regularly consuming wholegrain rye bread, the consumption of vegetables, fruit and berries was increased and this resulted in an increase of the mean plasma enterolactone level from 12.2 to $19.5 \mathrm{nmol} / \mathrm{l}$ but still only $30 \%$ of the subjects reached a level above $30 \mathrm{nmol} / 1$ and $35 \%$ still had levels below $15 \mathrm{nmol} / 1$ (Stumpf et al. 2000a).

Although wholegrain breads and cereals, vegetables and berries are related to serum enterolactone, they do not explain much of the variability of serum enterolactone. It is believed that the composition and activity of the bacterial flora on fermentation in the upper part of the colon plays a dominant role in the maintenance of serum enterolactone concentrations (Glits $\varnothing$ et al. 2000; Kilkkinen et al. 2001). Administration of antibiotics drastically reduces the levels (Adlercreutz et al. 1986; Kilkkinen et al. 2002) and after intake of antibiotics the pretreatment plasma concentration of enterolactone was not reached again for about 1 year. In the present study, serum enterolactone rebounded after 2 weeks in the single subject who took antibiotics while consuming the wholegrain diet. That the effect of antibiotics on gut flora may be an important factor in the aetiology of disease is shown by the recent study that observed that women taking several antibiotic courses for urinary tract infections had increased risk of breast cancer (Knekt et al. 2000). Whether lowering of plasma enterolactone concentration itself played a role in the increased risk for development of breast cancer is not known.

In summary, a diet high in foods containing wholegrain or wholemeal wheat, oats, rice and other grains caused an elevation in serum enterolactone.

\section{Acknowledgements}

This study was supported in part by MO1-RR00400 from the National Center for Research Resources and by T32 HL07779 from the National Heart, Lung, and Blood Institute. General Mills, Inc. (Golden Valley, MN, USA) supplied some of the breakfast cereals and the flour for muffins and cookies for both the wholegrain and refinedgrain diets and provided partial funding for laboratory analyses. H.A. gratefully acknowledges support from the Sigrid Juselius Foundation, Helsinki, Finland.

\section{References}

Adlercreutz H, Fotsis T, Bannwart C, Wahala K, Makela T, Brunow G \& Hase T (1986) Determination of urinary lignans and phytoestrogen metabolites, potential antiestrogens and anticarcinogens, in urine of women on various habitual diets. Journal of Steroid Biochemistry 25, 791-797.

Adlercreutz H, Höckerstedt K, Bannwart C, Bloigu S, Hamalainen E, Fotsis T \& Ollus A (1987) Effect of dietary components, including lignans and phytoestrogens, on enterohepatic circulation and liver metabolism of estrogens, and on sex hormone binding globulin (SHBG). Journal of Steroid Biochemistry 27, 1135-1144.

Adlercreutz H, Wang GJJ, Lapcik O, Hampl R, Wahala K, Makela T, Lusa K, Talme M \& Mikola H (1998) Time-resolved fluoroimmunoassay for plasma enterolactone. Analytical Biochemistry 265, 208-215.
Borriello SP, Setchell KDR, Axelson M \& Lawson AM (1985) Production and metabolism of lignans by the human faecal flora. Journal of Applied Bacteriology 58, 37-43.

Ford JD, Davin LB \& Lewis NG (1999) Plant lignans and health: cancer chemoprevention and biotechnological opportunities. Basic Life Science 66, 675-694.

Gerrior S \& Bente L (2001) Nutrient Content of the US Food Supply, 1990-97. US Department of Agriculture, Report no. 54. Washington, DC: Center for Nutrition Policy and Promotion.

Glitsø LV, Mazur WM, Adlercreutz H, Wähälä K, Mäkelä T, Sandström B \& Bach Knudsen KE (2000) Intestinal metabolism of rye lignans in pigs. British Journal of Nutrition 84, 429-437.

Heinonen S, Nurmi T, Liukkonen K, Poutanen K, Wahala K, Deyama T, Nishibe S \& Adlercreutz H (2001) In vitro metabolism of plant lignans: new precursors of mammalian lignans enterolactone and enterodiol. Journal of Agricultural and Food Chemistry 49, 3178-3186.

Harris JA \& Benedict FG (1919) A biometric study of basal metabolism in man. In Carnegie Institution of Washington Publication 279. Washington DC: Carnegie Institution.

Jacobs DR, Meyer KA, Kushi LH \& Folsom AR (1998) Whole grain intake may reduce risk of coronary heart disease death in postmenopausal women: The Iowa Women's Health Study. American Journal of Clinical Nutrition 68, 248-257.

Jacobs DR, Meyer KA, Kushi LH \& Folsom AR (1999) Is whole grain intake associated with reduced total and cause-specific death rates in older women? The Iowa Women's Health Study. American Journal of Public Health 89, 322-329.

Juntunen KS, Mazur WM, Liukkonen KH, Uehara M, Poutanen KS, Adlercreutz HCT \& Mykkänen HM (2000) Consumption of wholemeal rye bread increases serum concentrations and urinary excretion of enterolactone compared with consumption of white wheat bread in healthy Finnish men and women. British Journal of Nutrition 84, 839-846.

Kilkkinen A, Pietinen P, Klaukka T, Virtamo J, Korhonen P \& Adlercreutz H (2002) Use of oral antimicrobials decreases serum enterolactone concentration. American Journal of Epidemiology 155, 472-477.

Kilkkinen A, Stumpf K, Pietinen P, Valsta LM, Tapanainen H \& Adlercreutz H (2001) Determinants of serum enterolactone concentration. American Journal of Clinical Nutrition 73, $1094-1100$.

Knekt P, Adlercreutz H, Rissanen H, Aromaa A, Teppo L \& Heliövaara M (2000) Does antibacterial treatment for urinary tract infection contribute to the risk of breast cancer? British Journal of Cancer 82, 1107-1110.

Krauss RM, Deckelbaum RJ, Ernst N, Fisher E, Howard BV, Knopp RH, Kotchen T, Lichtenstein AH, McGill HC, Pearson TA, Prewitt TE, Stone NJ, Horn LV \& Weinberg R (1996) Dietary guidelines for healthy American adults. A statement for health professionals from the Nutrition Committee, American Heart Association. Circulation 94, 1795-1800.

Mazur W \& Adlercreutz H (1998) Natural and anthropogenic environmental oestrogens: the scientific basis for risk assessment. Naturally occurring oestrogens in food. Pure and Applied Chemistry 70, 1759-1776.

Meyer KA, Kushi LH, Jacobs DR Jr, Slavin J, Sellers TA \& Folsom AR (2000) Carbohydrates, dietary fiber, and incident type 2 diabetes mellitus in older women. American Journal of Clinical Nutrition 71, 921-930.

Pereira MA, Jacobs DR, Slattery ML, Ruth K, Van Horn L, Hilner J \& Kushi LH (1998) The association of whole grain intake and fasting insulin in a biracial cohort of young adults: The CARDIA Study. CVD Prevention 1, 231-242.

Pereira MA, Jacobs DR Jr, Pins JJ, Raatz SK, Gross MD, Slavin 
JL \& Seaquist ER (2002) Effect of whole grains on insulin sensitivity in overweight hyperinsulinemic adults. American Journal of Clinical Nutrition 75, 848-855.

Pietinen P, Stumpf K, Männistö S, Kataja V \& Adlercreutz H (2001) Serum enterolactone and risk of breast cancer: a casecontrol study in eastern Finland. Cancer Epidemiology, Biomarkers and Prevention 10, 339-344.

Pins JJ, Pereira MA, Jacobs DR Jr, Marquart L, Keenman J \& Slaving JE (2001) Whole grains, cereal fiber, and chronic disease: possible biological mechanisms. In CRC Handbook of Dietary Fiber in Human Disease, 3rd ed, pp. 461-498 [GA Spiller, editor]. New York, NY: CRC Press.

Slavin JL, Martini MC, Jacobs DR \& Marquart L (1999) Plausible mechanisms for the protectiveness of whole grains. American Journal of Clinical Nutrition 70, Suppl., 459S-463S.

Stumpf K, Pietinen P, Puska P \& Adlercreutz H (2000a) Changes in serum enterolactone, genistein, and daidzein in a dietary intervention study in Finland. Cancer Epidemiology, Biomarkers and Prevention 9, 1369-1372.

Stumpf K, Uehara M, Nurmi T \& Adlercreutz H (2000b) Changes in the time-resolved fluoroimmunoassay of plasma enterolactone.
Cancer Epidemiology, Biomarkers and Prevention 284, $153-157$.

Thompson LU (1998) Experimental studies on lignans and cancer. Baillieres Clinical Endocrinology and Metabolism 12, 691-705.

Tikkanen MJ \& Adlercreutz H (2000) Dietary soy-derived isoflavone phytoestrogens - Could they have a role in coronary heart disease prevention? Biochemical Pharmacology 60, 1-5.

Vanharanta M, Voutilainen S, Lakka TA, van der Lee M, Adlercreutz H \& Salonen JT (1999) Risk of acute coronary events according to serum concentrations of enterolactone: a prospective population-based case-control study. Lancet 354, 2112-2115.

Wiseman H (1999) Importance of oestrogen, xenoestrogen and phytoestrogen metabolism in breast cancer risk. Biochemical Society Transactions 27, 299-304.

Wiseman H, O'Reilly JD, Adlercreutz H, Mallet AI, Bowey EA, Rowland IR \& Sanders TA (2000) Isoflavone phytoestrogens consumed in soy decrease F-2-isoprostane concentrations and increase resistance of low-density lipoprotein to oxidation in humans. American Journal of Clinical Nutrition 72, 395-400. 